\title{
Dimeric and Trimeric Catenation of Giant Chiral [8+12] Imine Cubes Driven by Weak Supramolecular Interactions
}

\author{
Bahiru Punja Benke, Tobias Kirschbaum, Jürgen Graf, Michael Mastalerz* \\ Organisch-Chemisches Institut, Ruprecht-Karls-Universität Heidelberg, Im Neuenheimer Feld \\ 270, 69120 Heidelberg, Germany \\ Email: michael.mastalerz@oci.uni-heidelberg.de
}

\begin{abstract}
Mechanically interlocked structures, such as catenanes or rotaxanes are fascinating synthetic targets and are the basis of molecular switches and machines. Today, the vast majority of catenated structures are built upon macrocycles and only a very few examples of threedimensional shape-persistent organic cages forming such structures are reported. However, the catenation in all these cases was based on a thermodynamically favoured $\pi$ - $\pi$ stacking under certain reaction conditions. Here, we present our findings that catenane formation can be driven by even less directional dispersion (Keesom) interactions of methoxy-groups during the synthesis of chiral [8+12] imine cubes, giving dimeric and also for the first time trimeric catenated organic cages. To further elucidate the underlying driving forces, twelve differently 1,4-substituted benzene dialdehydes have been reacted with a chiral triamino tribenzotriquinacene under various conditions to study whether monomeric cages or catenated cage dimers are the preferred products.
\end{abstract}

\section{Main}

Since the first report of Wasserman in the early 1960s of a catenane as a statistical occurring by-product during a macrocyclization via benzoin condensation, ${ }^{1}$ the interest in interlocked molecular structures developed rapidly in the last decades, ${ }^{2,3}$ especially because such compounds build the fundamental knowledge for molecular switches and machines.,5,6 Although Lüttringhaus and Schill introduced already rational synthetic approaches towards a 
number of interlocked structures in the $1960 \mathrm{~s},{ }^{7}$ the real ignition of this research field began with the work by Jean-Pierre Sauvage and coworkers with a high-yielding catenane synthesis exploiting the templated coordination of two molecular strands by a metal ion before closing these to two interlocked macrocycles via Williamson ether synthesis ${ }^{8}{ }^{89}$ This concept of using a template was and still is the most frequently applied strategy for the synthesis of more complex interlocked structures such as borromean rings, ${ }^{10}$ various knots, ${ }^{11,12,13,14}$ a Star of David catenane,${ }^{15}$ poly[n]catenanes, ${ }^{16}$ or interlocked coordination cages. ${ }^{17,18,19,20,21}$ Besides ligand to metal ion coordination also weaker and less directing supramolecular interactions, such as hydrogen bonding or $\pi-\pi$ stacking have been used to arrange molecular precursors in the right fashion to synthesize interlocked structures. ${ }^{22}$

In contrast to the relative large number and diversity of interlocked coordination cages, ${ }^{18}$ there are still only a few examples of purely organic cage catenanes reported to date. The first example was reported by Beer et al. ${ }^{23}$ They exploited a template effect of sulfate anions, interacting with carbamate units to prearrange two tripodal precursor molecules in such a way that by the end-capping of these via a copper-mediated 1,3-dipolar cycloaddition a triply interlocked cage dimer was formed in $21 \%$ yield. One year later, in 2010, Cooper and coworkers described that by changing conditions for the synthesis of a [4+6] imine cage by adding catalytic amounts of trifluoroacetic acid to the reaction solution in acetonitrile or dichloromethane, these $[4+6]$ imine cages form triply interlocked dimers, ${ }^{24}$ which was proven by single-crystal X-ray diffraction. It was suggested that $\pi$ - $\pi$ stacking most probably is the driving force for the catenane formation and if a competing aromatic solvent was present in certain amounts, this indeed suppressed the catenane formation. In 2014, the formation of a quadruply interlocked dimer of giant $[12+8]$ boronic ester cage was described ${ }^{25}$ which was clearly characterized by singlecrystal X-ray diffraction. The only difference between the interlocked cage dimer and a corresponding monomeric $[12+8]$ boronic ester cage ${ }^{26}$ published before is the position and length of solubilizing alkyl-chains in the molecular precursors, which led to the hypothesis that 
additionally weak dispersion interactions may be responsible for the catenane formation to overcome any entropic penalty. Similar but more distinct, this entropic penalty was balanced by dispersion interactions in the formation of a hydrocarbon cage and its catenated dimer made by alkyne metathesis. ${ }^{27}$ Depending on concentration of reacting monomers, the equilibrium between monomeric and interlocked cage could be shifted towards the one or the other metathesis product. The authors assumed that a triply interlocked structure is energetically more favored than a singly one due to a maximization of filled space. 2015, Li et al. exploited the hydrophobic effect to achieve an interlocked cage dimer via a hydrazone bond formation in water. ${ }^{28}$ Very recently, the group of Shaodong Zhang presented the formation of a triply interlocked catenane of a [2+3] imine cage. ${ }^{29,30}$ Again, it was concluded that the driving force is the energetic benefits of additional $\pi-\pi$ stacking. In contrast to the before mentioned examples, here the dimer formation has been studied more detailed by kinetic NMR measurements and time-dependent mass spectroscopy; however, no thermodynamic assumptions were corroborated by experiments.

During our ongoing work on using chiral triamino tribenzotriquinacenes (TBTQs) in the condensation with aromatic aldehydes to study self-sorting of cages, ${ }^{31,32}$ we serendipity found an unprecedented substituent driven formation of dimeric and trimeric cage catenanes by very weak supramolecular interactions, which is described herein.

\section{Results and Discussion}

Inspired by Warmuth's chiral cube, ${ }^{33}$ based on the condensation of eight molecules of cyclotriveratrylene (CTV) trisaldehyde and para-phenylene diamine we intended to use a chiral TBTQ precursor instead, which is in contrast to the CTV structurally fixed and cannot racemise during cage formation. Indeed, the condensation of enantiopure triamino TBTQ $(P)-\mathbf{1}^{34}$ with 2,4-dihydroxy terephthalaldehyde 2 under typical conditions we used before for similar systems 
(cat. TFA, $\mathrm{CDCl}_{3}$ room temperature) ${ }^{33,35}$ gave clean chiral [8+12] cage $\mathbf{O H - c u b e}$ in $88 \%$ isolated yield (Fig. 1) and was identified by NMR spectroscopy and mass spectrometry.

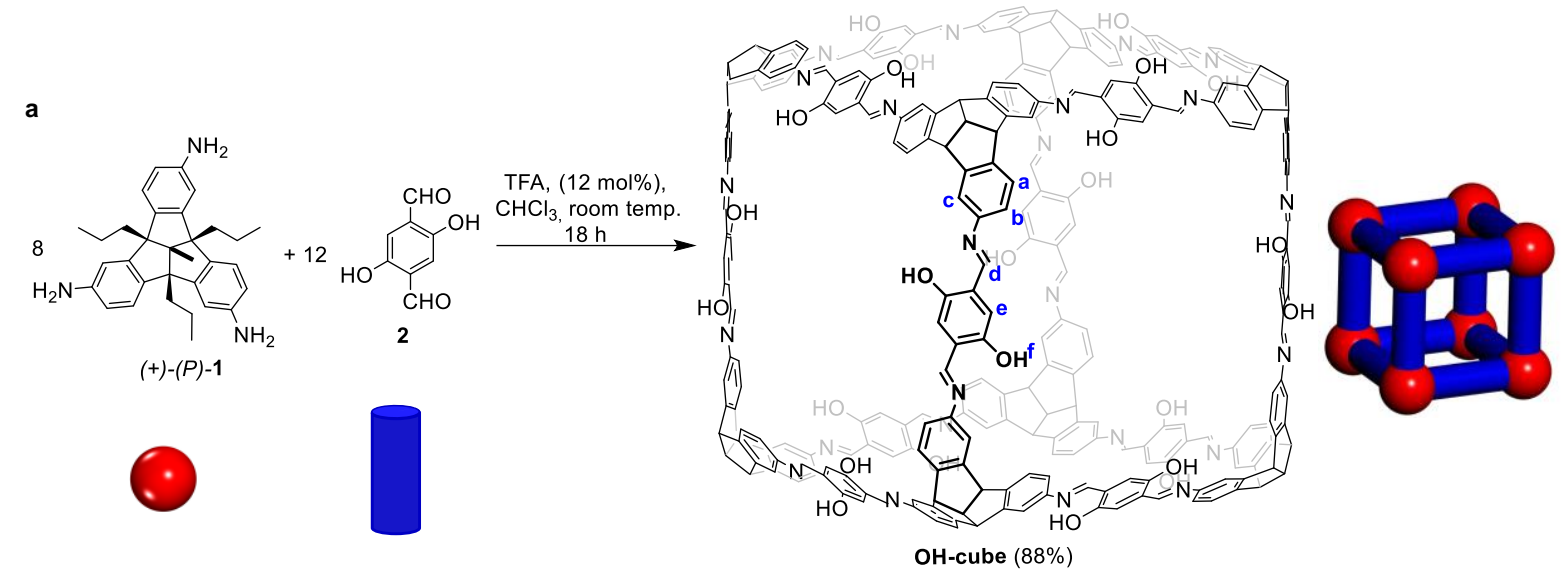

b

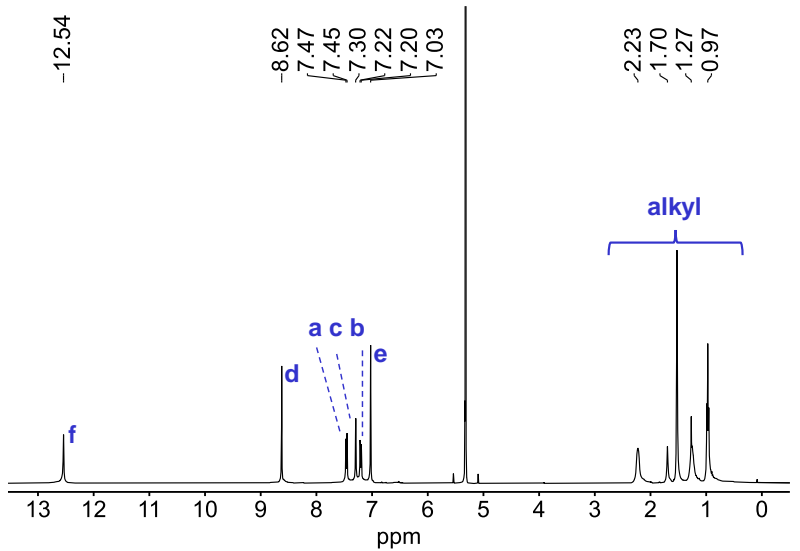

c

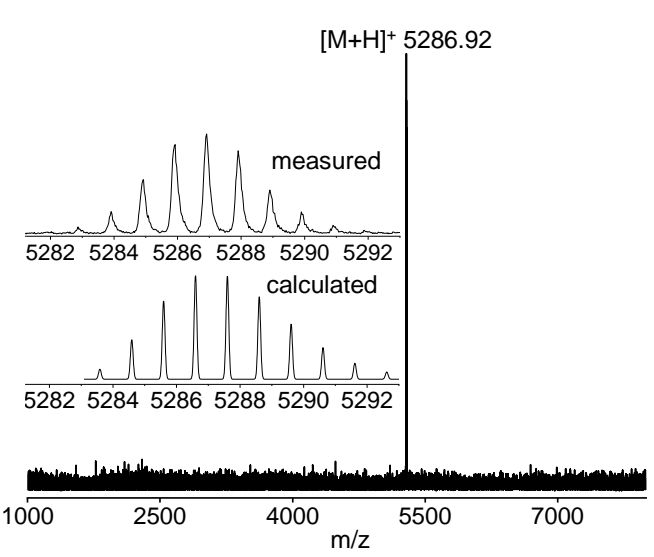

Figure 1. Synthesis and Characterization of Chiral Cage OH-cube. a Schematic representation of the acid catalysed 24-fold imine condensation of chiral TBTQ amine 1 and 2,5-dihydroxy terephthalaldehyde 2 to OHcube. Please note that on the final cubic structure any alkyl substituents are omitted for clarity. Reactants and cube are also drawn as cartoons. Red balls represent the TBTQ units and blue struts the aldehyde or imine linker units. b ${ }^{1} \mathrm{H}$ NMR spectrum (500 MHz, $\mathrm{CD}_{2} \mathrm{Cl}_{2}$, room temp.) of $\mathbf{O H}$-cube. For assignment see molecular structure OH-cube on top and Supporting Information. c MALDI-TOF MS (dithranol) of OH-cube. The inset shows the measured isotopic pattern of the mass peak and the calculated pattern for $\mathbf{O H}$-cube in comparison.

Originally we were interested in post-stabilizing the $\mathbf{O H}$-cube by Pinnick-oxidation to turn imine bonds into amide bonds. ${ }^{36}$ As reported before, this does not work with the phenolic hydroxy groups present. To avoid a 24-fold post-synthetic Williamson etherification on $\mathbf{O H}$ cube ${ }^{37}$ we instead condensed TBTQ $(P)-\mathbf{1}$ with dimethoxy terephthalaldehyde $\mathbf{3}$ under the same conditions (Fig. 2a). In contrast to the reaction with aldehyde 2 , here the ${ }^{1} \mathrm{H}$ NMR spectrum of the crude product was very complex with a large number of peaks in the aromatic 
as well as in the aliphatic region (Fig. 2b). The corresponding MALDI-TOF MS revealed that beside the $[8+12]$ OMe-cube $(m / z=5623.24)$, a $[16+24]$ condensation product $(\mathrm{m} / \mathrm{z}=$ 11245.57) was found and even a small peak with $\mathrm{m} / \mathrm{z}=16868.52$ was detected (Fig. 2c), suggesting that a larger [24+36] species may have formed. Taking into consideration the complex ${ }^{1} \mathrm{H}$ NMR spectra reported for triply interlocked cages before, ${ }^{24}$ it was assumed that these species are most likely catenated dimer (OMe-cube)2 and trimer (OMe-cube) 3 rather than larger more symmetric and non-interlocked species. By applying recycling gel permeation chromatography (r-GPC) with dichloromethane as solvent, it was possible to separate the three compounds after multiple cycles (Fig. 2d, for details, see Supplementary Information).
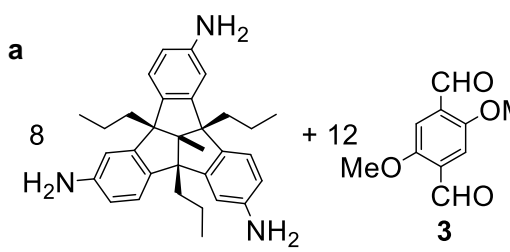

TFA, (12 mol\%),
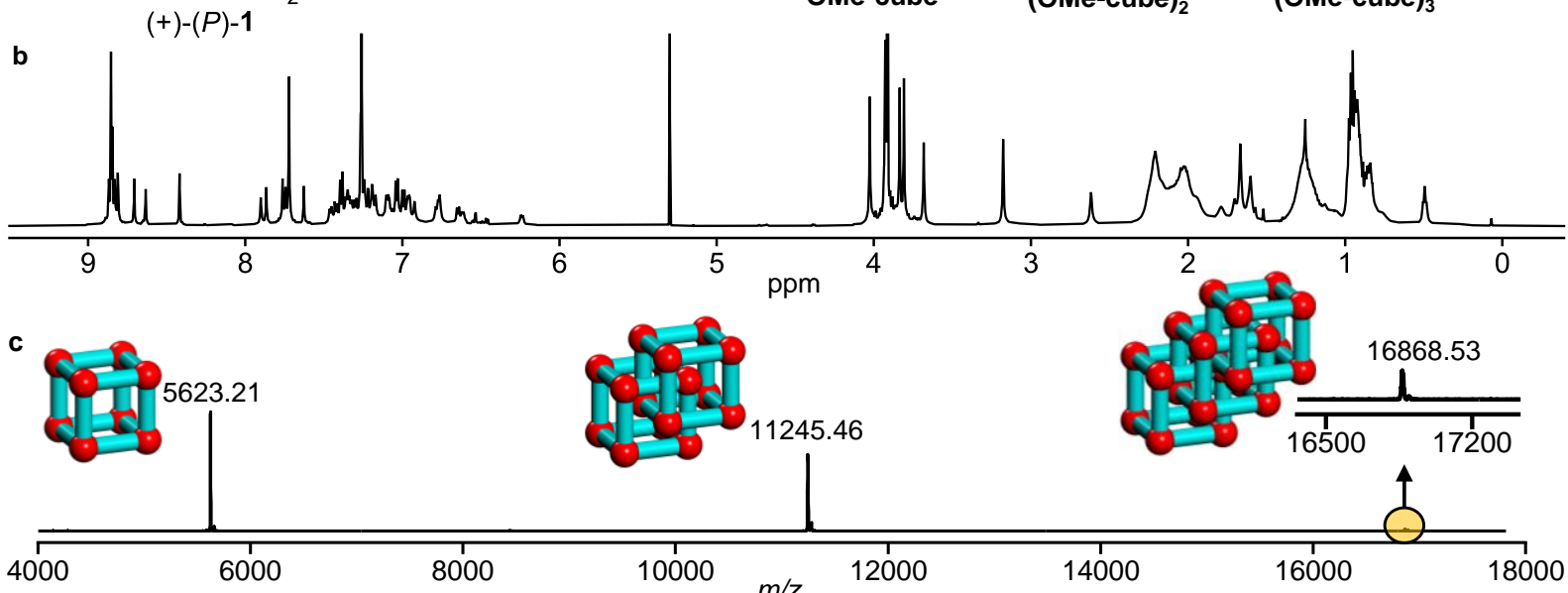

d

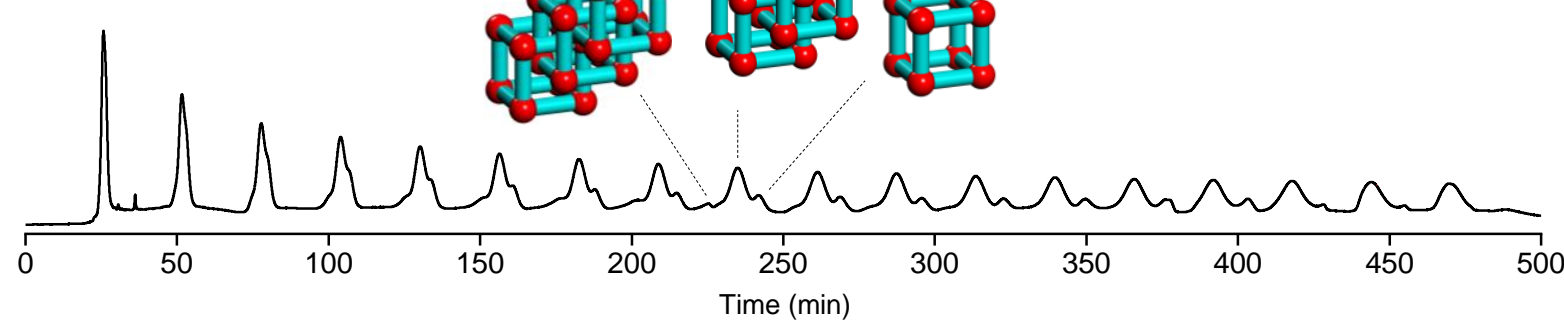

Figure 2. Reaction of Triamine 1 and Dimethoxydialdehyde 3 to Catenated Cages. a Schematic representation of the acid catalysed 24-fold imine condensation of $\mathbf{1}$ and $\mathbf{2}$ to OMe-cubes. $\mathbf{b}$ and $\mathbf{c}^{1} \mathrm{H} \mathrm{NMR}\left(600 \mathrm{MHz}, \mathrm{CDCl}_{3}\right)$ and MALDI-TOF MS (DCTB) of crude reaction mixture of OMe-cubes. d r-GPC traces (solvent DCM) of the crude mixture of OMe-cube, (OMe-cube) 2 and (OMe-cube) $)_{3}$. 
As described in literature before, the equilibrium between monomeric and catenated cage shifts towards the latter by increasing the concentration of reactants and vice versa to the monomeric cage by decreasing it. Therefore, a screening of the reaction at different concentrations (between $0.42 \mathrm{mM}$ and $42.8 \mathrm{mM}$ ) was performed and analyzed mainly by MALDI-TOF MS (Supplementary Table 1). As expected, with higher concentration more catenated compounds (OMe-cube) $)_{2}$ and (OMe-cube $)_{3}$ are found and the concentration needs to be $0.42 \mathrm{mM}$ or below that to avoid the formation of those and to form monomeric cage OMe-cube exclusively. For comparison; reactions with dihydroxy terephthaldehyde $\mathbf{2}$ gave under no concentration (up to $42.8 \mathrm{mM}$ ) any catenated species at all and in each experiment only monomeric cage OH-cube was detected by ${ }^{1} \mathrm{H}$ NMR spectroscopy (Supplementary Fig.248). It is worth mentioning that as soon as a solution of monomeric cage OMe-cube was concentrated by rotary evaporation $\left(50{ }^{\circ} \mathrm{C}\right.$, reduced pressure), the equilibrium immediately shifted towards the catenated products (OMe-cube) 2 and (OMe-cube) 3 as found by NMR and r-GPC analysis. On one hand, this clearly demonstrated the dynamic covalent chemistry character and thus thermodynamically driven formation of the catenane. ${ }^{38}$ On the other hand, it made the separation and characterization of monomeric cage OMe-cube more challenging. Despite of these findings, we were able to develop a synthetic protocol to isolate OMe-cube in $85 \%$ yield, avoiding long reaction times, certain concentration and temperature thresholds and exploiting the low solubility of the cage in acetonitrile (Fig. 3a and Supplementary Information). On the other hand, running the reaction of $\mathbf{3}$ and $\mathbf{1}$ in dichloromethane instead of $\mathrm{CHCl}_{3}$ at $10 \mathrm{mM}$ concentration and $80{ }^{\circ} \mathrm{C}$ for 3 days allowed us to push the equilibrium towards the tricatenane (OMe-cube)3, which was isolated in $80 \%$ yield (Fig. 3a). The best results for the dimeric cage (OMe-cube)2, was achieved, when dialdehyde 3 and triamine 1 were reacted at $10 \mathrm{mM}$ scale. However, it still needed to be separated by r-GPC from OMe-cube and (OMe-cube) 3 at $35{ }^{\circ} \mathrm{C}$ to be obtained in $47 \%$ isolated yield (Fig. 3a). 
After reinjection the once separated fractions each again, three distinct peaks each of nearly Gaussian shape with retention times of $25.0 \mathrm{~min}\left(1^{\text {st }}\right.$ fraction $), 25.5 \mathrm{~min}\left(2^{\text {nd }}\right)$ and 26.0 minutes $\left(3^{\text {rd }}\right)$ were detected (Figs. 3b, d and f). MALDI-TOF MS analysis of each fraction (Fig. 3c, e, and g) now show single peaks exclusively at $m / z=16868.52\left(1^{\text {st }}\right.$ fraction $), m / z=11245.57\left(2^{\text {nd }}\right.$ fraction) and $m / z=5623.57$ ( $3^{\text {rd }}$ fraction) which exactly fit to a [24+36], a [16+24] and a [8+12] species. The ${ }^{1} \mathrm{H}$ NMR spectrum (Fig. $3 \mathrm{~h}$ ) of the $3^{\text {rd }}$ fraction was very simple, showing signals comparable to $\mathbf{O H}$-cube and in combination with the mass spectrum this compound was clearly identified as the monomeric chiral [8+12] OMe-cube. By diffusion-ordered NMR spectroscopy (DOSY) in deuterated dichloromethane at $295 \mathrm{~K}$ only one trace was detected with a diffusion coefficient of $D=5.25 \cdot 10^{-10} \mathrm{~m}^{2} \mathrm{~s}^{-1}$ which corresponds according the uncorrected StokesEinstein equation to a solvodynamic radius of $r_{\mathrm{S}}=10.1 \AA$ (Supplementary Fig. 187). In contrast to the relatively simple ${ }^{1} \mathrm{H}$ NMR spectrum of monomeric OMe-cube (Fig. 3h), the one of the [16+24] species was much more complex (Fig. 3i). Nevertheless, despite the large number of signals, most of them are sharp and did not superimpose, allowing a more detailed analysis of the structure (Fig. 4a and for detail structural analysis see Supplementary Information). By 2D NMR experiments, eight different types of imine-protons and eight different methoxy-protons were identified (Figs. 4b and 4c). This is exactly the number expected for a triply interlocked cage dimer (see model in Figs. 4h-i.) A singly interlocked dimer can clearly be ruled out. Here, two sets of twelve instead of eight peaks would be expected (Supplementary Fig. 329). By DOSY NMR in dichloromethane at $295 \mathrm{~K}$ only one trace of signals for (OMe-cube) 2 confirmed that this is a single species. The diffusion coefficient $D=4.27 \times 10^{-10} \mathrm{~m}^{2} \mathrm{~s}^{-1}$ corresponds to a solvodynamic radius of $12.3 \AA$ (Supplementary Fig. 188). This is slightly larger than for OMecube $(10.1 \AA)$ which is consistence with its slightly larger size. 


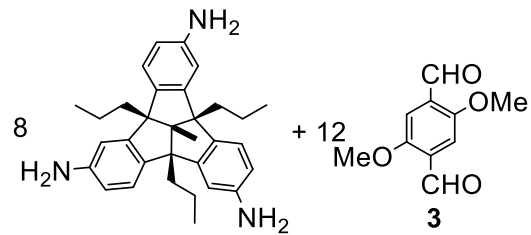

$(+)-(P)-1$

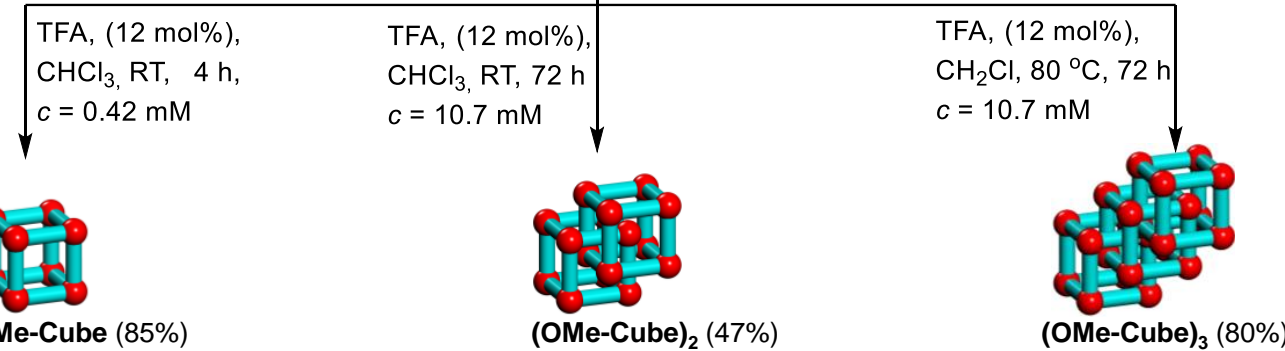

c $\quad 5623.24$

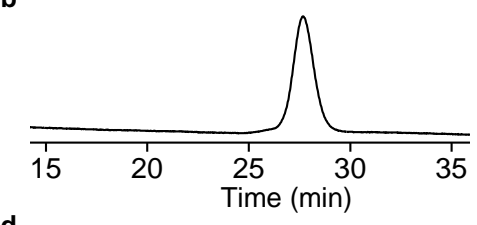

(OMe-Cube) $3(80 \%)$

d

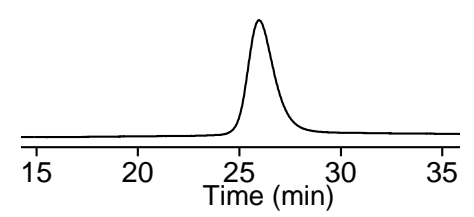

4000

f

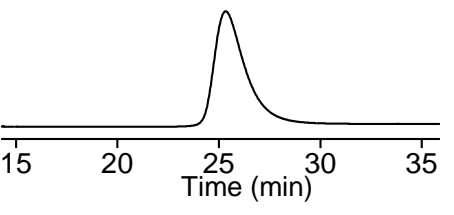

h

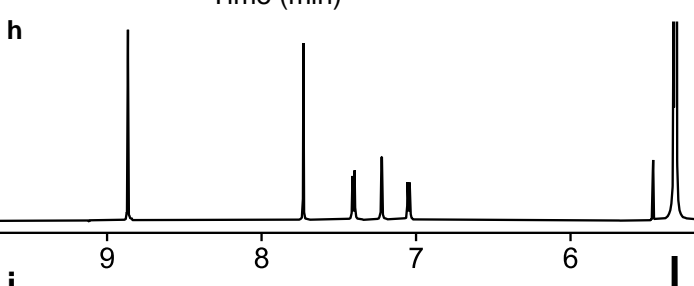

g

i

1
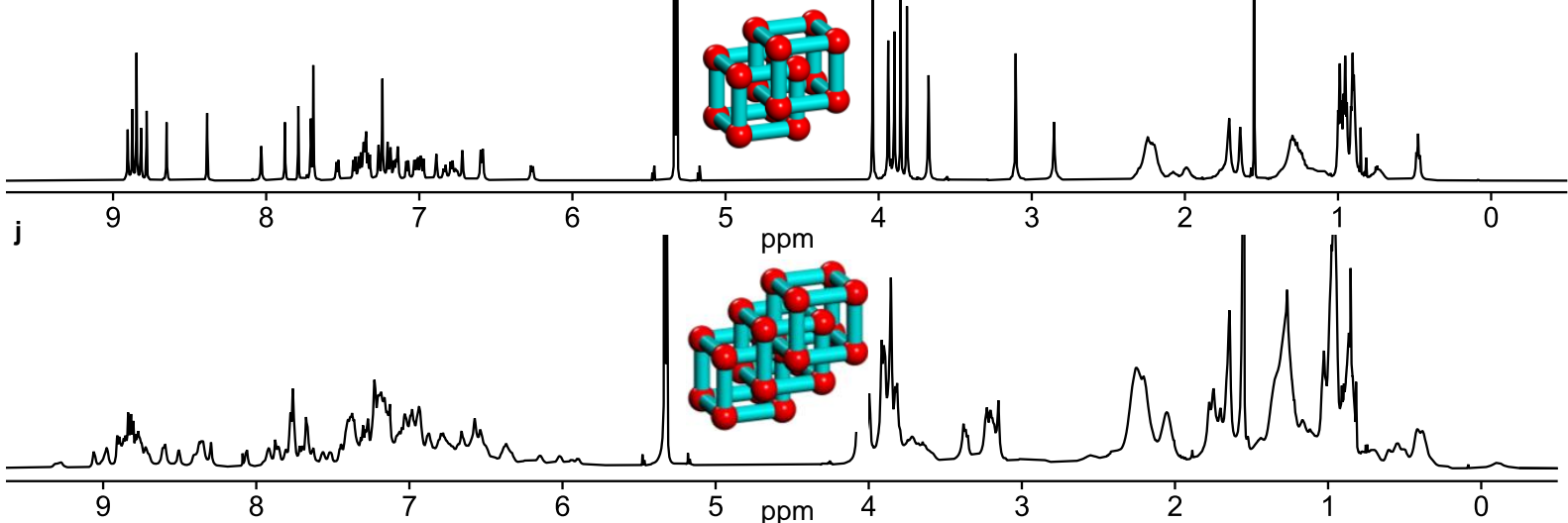

Figure 3. Selective Reactions of Triamine 1 and Dimethoxydialdehyde 3 to Catenated Cages. a Schematic representation of the acid catalysed 24-fold imine condensation of $\mathbf{1}$ and $\mathbf{2}$ to OMe-cube, (OMe-cube) 2 and (OMe-cube) $)_{3}$. For reaction details, see Supporting Information. b, d, f r-GPC-traces of pure OMe-cube, (OMecube) $)_{2}$ and (OMe-cube) $)_{3}$. Depicted is the $1^{\text {st }}$ cycle, each. c, e, g corresponding MALDI-TOF mass spectra of OMecube, (OMe-cube) ${ }_{2}$ and (OMe-cube) $)_{3} \mathbf{h}, \mathbf{i}, \mathbf{j}^{1}{ }^{1} \mathrm{H}$ NMR spectra $\left(600 \mathrm{MHz}\right.$ ) of pure OMe-cube, (OMe-cube) ${ }_{2}$ and (OMe-cube) 3 . 

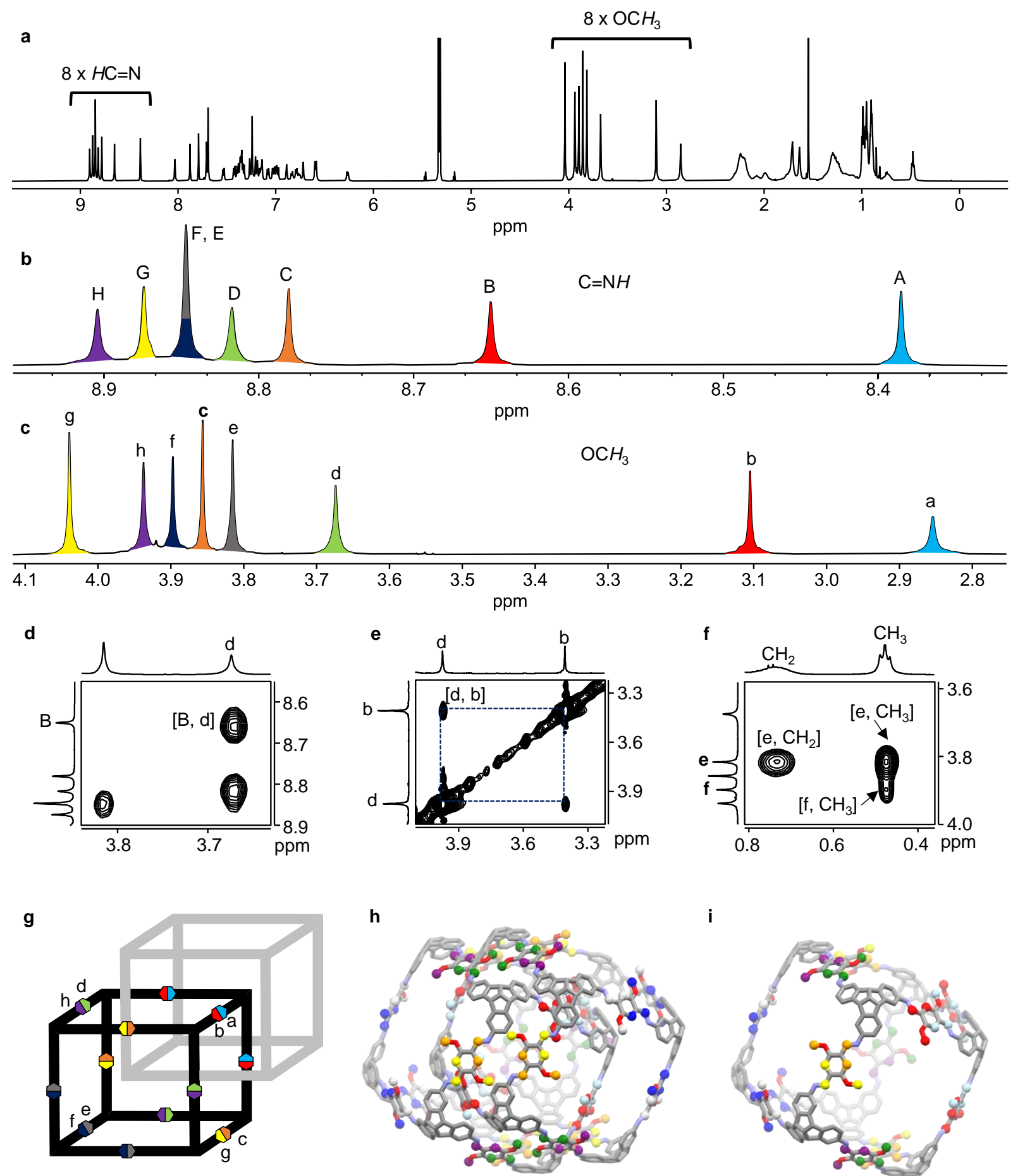

Figure 4. NMR Spectroscopic Analysis of (OMe-cube)2. a Full ${ }^{1} \mathrm{H} N M R\left(600 \mathrm{MHz}, \mathrm{CDCl}_{3}\right.$ ) spectrum of (OMe-cube)2. Partial ${ }^{1} \mathrm{H}$ NMR ( $600 \mathrm{MHz}, \mathrm{CDCl}_{3}$ ) showing eight different types of $\mathbf{b}$ imine peaks and $\mathbf{c}$ methoxy peaks of (OMecube)2. d NOESY spectrum showing cross peaks between imine proton B and methoxy proton d. e NOESY spectrum showing cross peaks between methoxy protons $b$ and $d$. f NOESY spectrum showing cross peaks between highly shielded aliphatic protons and methoxy protons e and f. $\mathbf{g}$ cartoon of the catenated cube highlighting the different magnetically equivalent positions at the linker units. The color code and assignment is the same as in $\mathbf{b}$ and $\mathbf{c}$. $\mathbf{h}$. Structural model of triply interlocked (OMe-cube) $\mathbf{2}$ based on NMR studies with the same color code for the assignment as in $\mathbf{g}$. i single cube for clarity reasons. 
The trimeric interlocked cage (OMe-cube)3 shows unfortunately much less resolved multiple broad peaks in the ${ }^{1} \mathrm{H}$ NMR spectrum in contrast to dimer (OMe-cube)2. Independent if this compound is a chain-like catenane (OMe-cube)@(OMe-cube)@(OMe-cube) or a multiple catenane [(OMe-cube)@(OMe-cube)]@(OMe-cube) (for models, see Supplementary Figs. 336 and 337) a total number of 72 imine proton peaks are expected due to the lack of any applicable symmetry operations $\left(C_{1}\right.$-symmetry). The same is true for all other chemically 'equivalent' protons making it very difficult or even impossible to distinguish between the two possibilities. Furthermore, the generation of positional isomers cannot strictly be ruled out. However, since the trimeric catenane (OMe-cube)3 is still very good soluble under reaction conditions and no larger oligomers such as tetrameric and pentameric cages (OMe-cube)4 or (OMe-cube)5 are found by mass spectrometry, it seems to be more likely a multiple catenane [(OMe-cube)@(OMe-cube)]@(OMe-cube) and not a chainlike triple catenane (OMecube)@(OMe-cube)@(OMe-cube). If it would be the latter motif, we would expect at least some formation of longer oligomers. On the other hand, a multiple tetrameric catenane is out of steric reasons simply not possible, which once more favors the multiple catenane [(OMecube)@(OMe-cube)]@(OMe-cube) model. DOSY NMR of (OMe-cube)3 again shows a single trace with a diffusion coefficient $D=4.27 \times 10^{-10} \mathrm{~m}^{2} \mathrm{~s}^{-1}$. The calculated solvodynamic radius of $11.2 \AA$ was found to be almost similar with the dicatenane (OMe-cube) $2(12.3 \AA$ ) once more suggesting a tightly packed interlocked structure (Figure S189). It is worth mentioning that for $\mathbf{O H}$-cube, OMe-cube, (OMe-cube) 2 as well as (OMe-cube) 3 innumerous large single-crystals from various solvents have been obtained. Unfortunately, even with synchrotron radiation no resolution has been obtained to elucidate the solid state structures.

We were interested to get further insight into the driving force of the unique catenation of methoxy cage OMe-cube to dimer (OMe-cube) 2 and even to trimer (OMe-cube) 3 and why we do not see any such catenation for the hydroxyl substituted $\mathbf{O H}-$ cube under any concentration. 
Due to the triply interlocked catenation of dimer (OMe-cube) $\equiv($ OMe-cube) in favour of a possible singly interlocked dimer (OMe-cube)-(OMe-cube), the aforementioned $\pi$ - $\pi$ stacking as driving force, found for almost all other yet in literature described interlocked organic cages, was excluded (see above), otherwise singly interlocked catenation should have been formed preferably. If $\pi$ - $\pi$ stacking would have been the driving force, for $\mathbf{O H}$-cube a higher tendency of dimerization would have been expected than for OMe-cube, because intramolecular Hbonding of the hydroxyl imine is stiffening the $\pi$-backbone and strongly enhances intermolecular $\pi-\pi$ stacking. ${ }^{39}$ This assumption is strengthened by the fact that under various reaction conditions (different acid concentration, different concentration of reactants, different solvents, different and elevated temperature, different reaction times (up to several months!) no catenane formation was found for $\mathbf{O H}$-cube (Supplementary Information). A kinetic formation driven by precipitation was also ruled out, because the reaction mixture of $\mathbf{1}, \mathbf{2}$ and $\mathbf{O H}$-cube were at all times clear solutions. ${ }^{38}$

Since $\pi$-stacking was ruled out as driving force, it was hypothesized that dipole-dipole induced dispersion interactions (so-called Keesom interactions) ${ }^{40}$ of the methoxy groups are responsible for the catenation as e.g. found in single crystals of methoxy-substituted $\pi$-systems $\left(d\left(\mathrm{MeO}{ }^{\cdots} \mathrm{CH}_{3} \mathrm{O}\right)=3.1 \AA\right) .{ }^{41}$ In this respect, it is worth mentioning that Cooper et al. described the unexpected formation of a knot, when originally achieving cages based on dimethoxy terephthaldehyde $3,{ }^{42}$ which may rely on the same weak interactions. Indeed, a closer look at the X-ray structure show the same methoxy methoxy interacting motif, albeit with a larger distance between the functional groups of $d\left(\mathrm{MeO}{ }^{\cdots} \mathrm{CH}_{3} \mathrm{O}\right)=3.5 \AA$ (Supplementary Fig. 330). Conformational analysis by DFT calculations (Chapter 13 Supplementary Information) of OMe-cube as well as NOESY cross peaks of imine $\mathrm{CH}$ and the aromatic TBTQ protons revealed a low barrier of rotation of the linker units at room temperature, which is also present in the triply interlocked dimer (OMe-cube) 2 allowing the mechanically interlocked molecule to adopt conformations that have three such methoxy-methoxy interactions (Fig. 5c). 
If methoxy groups are absent, no catenane formation should occur. Thus triamine $\mathbf{1}$ was reacted with non-substituted terephthalaldehyde 4 (Fig. 5a) under different conditions (various solvents, Supplementary Fig. 252) and no catenane formation was observed. Pure H-cube was isolated in $90 \%$ from THF. By adding two methyl substituents instead of two methoxy groups to the aldehyde (5) still almost no catenane formation is observed by ${ }^{1} \mathrm{H}$ NMR (Supplementary Fig. 253) and monomeric Me-cube is formed in $84 \%$ yield. As soon as the alkyl substituents at the dialdehyde precursor (6) get longer (here ethyl), the possibility of intermolecular dispersion interactions $^{43}$ (Fig. 5b) is increased and now some catenane (Et-cube) 2 was found by ${ }^{1} \mathrm{H}$ NMR spectroscopy as well as MS (Supplementary Fig. 254) besides monomeric Et-cube (which still is the main product). Comparing the different results of Me-cube versus Et-cube, based on the simple elongation of the alkyl chains by one methylene unit each, electronic effects to foster $\pi$ $\pi$-stacking can be ruled out, because the methyl- as well as the ethyl-substituents have almost the same Hammett parameters $\left(\sigma_{\mathrm{m}}(\mathrm{Me})=-0.07 ; \sigma_{\mathrm{m}}(\mathrm{Et})=-0.07 ; \sigma_{\mathrm{p}}(\mathrm{Me})=-0.17 ; \sigma_{\mathrm{p}}(\mathrm{Et})=-\right.$ 0.15). ${ }^{44}$ As for OMe-cube and (OMe-cube)2, the ratio of catenane (Et-cube) 2 versus monomeric cage Et-cube was also strongly solvent dependent for the reaction of triamine $\mathbf{1}$ and aldehyde 6 and in THF the amount of catenane was higher than e.g. in $\mathrm{CHCl}_{3}$ and both compounds (monomer and catenane) were selectivity achieved by adjusting the conditions. The reaction in $\mathrm{CHCl}_{3}$ at room temperature gave monomeric cage Et-cube in $75 \%$ isolated yields, whereas running the reaction in THF gave after separation 35\% of the catenated dimer (Etcube) 2 in pure form.

To further exclude pure electronic effects, we reacted triamine $\mathbf{1}$ with diethoxy- and diisopropoxy dialdehydes $\mathbf{7}$ and $\mathbf{8}$, (Fig. 5a) where the substituents have comparable Hammett parameter as in dimethoxy dialdehyde $3\left(\sigma_{\mathrm{m}}(\mathrm{OMe})=0.12 ; \sigma_{\mathrm{m}}(\mathrm{OEt})=0.10 ; \sigma_{\mathrm{m}}\left(\mathrm{O}^{\mathrm{i}} \mathrm{Pr}\right)=0.10\right)$, but are of different steric demand. Whereas for the diethoxy dialdehyde 7 some catenane formation of (OEt-cube)2 was observed, for diisopropoxy dialdehyde $\mathbf{8}$ no catenane (OiPrcube)2 occurred (Supplementary Fig.255 and 256), supporting once more the hypothesis that 
the catenane formation is mainly driven by additional weak dipole-dipole or dispersion interactions and in case of the latter steric repulsion is stronger than the weak attraction (Figure 5b, Charton steric parameter for Me, Et, and ${ }^{i} \operatorname{Pr}$ are $\left.v_{\mathrm{Me}}=0.52 ; v_{\mathrm{Et}}=0.56 ; v_{\mathrm{iPr}}=0.76\right) .{ }^{45}$ By increasing these weak interactions, the equilibrium may be shifted towards the interlocked structures. Sulfur containing organic compounds are known to interact via sulfur-sulfur interactions. ${ }^{46}$ And indeed, by using dimethylthioether $\mathbf{9}$ in the condensation with triamine $\mathbf{1}$ in $\mathrm{CDCl}_{3}$ almost exclusively the catenated dimer (SMe-cube)2 was formed (Fig. 5a and Supplementary Fig. 257). Again, to rule out electronic effects based on the thioalkyl substituent donating to the aromatic dialdehyde, di-tert-butylthioether substituted dialdehyde $\mathbf{1 0}$ with two sterically demanding tert-butyl groups was investigated in the reaction $\left(v_{\mathrm{Me}}=0.52 \mathrm{vs} v_{\mathrm{tBu}}=\right.$ 1.24). ${ }^{45}$ As expected, only clean monomeric $\mathbf{S C}\left(\mathbf{C H}_{3}\right)_{3}$-cube was formed and isolated in $75 \%$ yield (Supplementary Fig.258). Finally, we investigated the reaction of dibromo dialdehyde 11 with triamine $\mathbf{1}$, to see whether halogen bond formation ${ }^{47}$ can also induce catenation. Although the mass spectrum of the reaction mixture in $\mathrm{CD}_{2} \mathrm{Cl}_{2}$ showed a pronounced peak at $\mathrm{m} / \mathrm{z}=$ 13591.6, which is the double amount of the monomeric Br-cube $(\mathrm{m} / \mathrm{z}=6796.4)$, in the correlated ${ }^{1} \mathrm{H}$ NMR spectrum only small detectable peaks of any interlocked species are present besides mainly those signals of pure monomeric Br-cube (Supplementary Fig.259). However, in contrast to all other reactions, here a precipitate was formed of very low solubility, which may contain insoluble (Br-cube)2.

To correlate the weak interactions responsible for catenation, the systems where catenation occurred have been studied by concentration dependent NMR spectroscopy (see Supplementary information), to estimate the Gibb's enthalpy of cage to catenane transformation. With $\Delta G_{298}=-26.7 \mathrm{~kJ} / \mathrm{mol}$ the reaction of 2 SMe-cube $\rightarrow(\text { SMe-cube })_{2}$ is about $6 \mathrm{~kJ} / \mathrm{mol}$ higher as for the methoxy cages 2 Me-cube $\left.\rightarrow(\text { OMe-cube })_{2}, \Delta G_{298}=-20.8 \mathrm{~kJ} / \mathrm{mol}\right)$ and almost $10 \mathrm{~kJ} / \mathrm{mol}$ higher than found for the ethoxy cages 2 OEt-cube $\rightarrow$ (OEt-cube)2, $\Delta G_{298}=-15.7 \mathrm{~kJ} / \mathrm{mol}$ ) (Fig. 5d), which is the same trend as expected for these weak 
interactions. ${ }^{46}$ Unfortunately, the amount of (Et-cube)2 besides Et-cube was too small to determine reliable numbers by this method. 


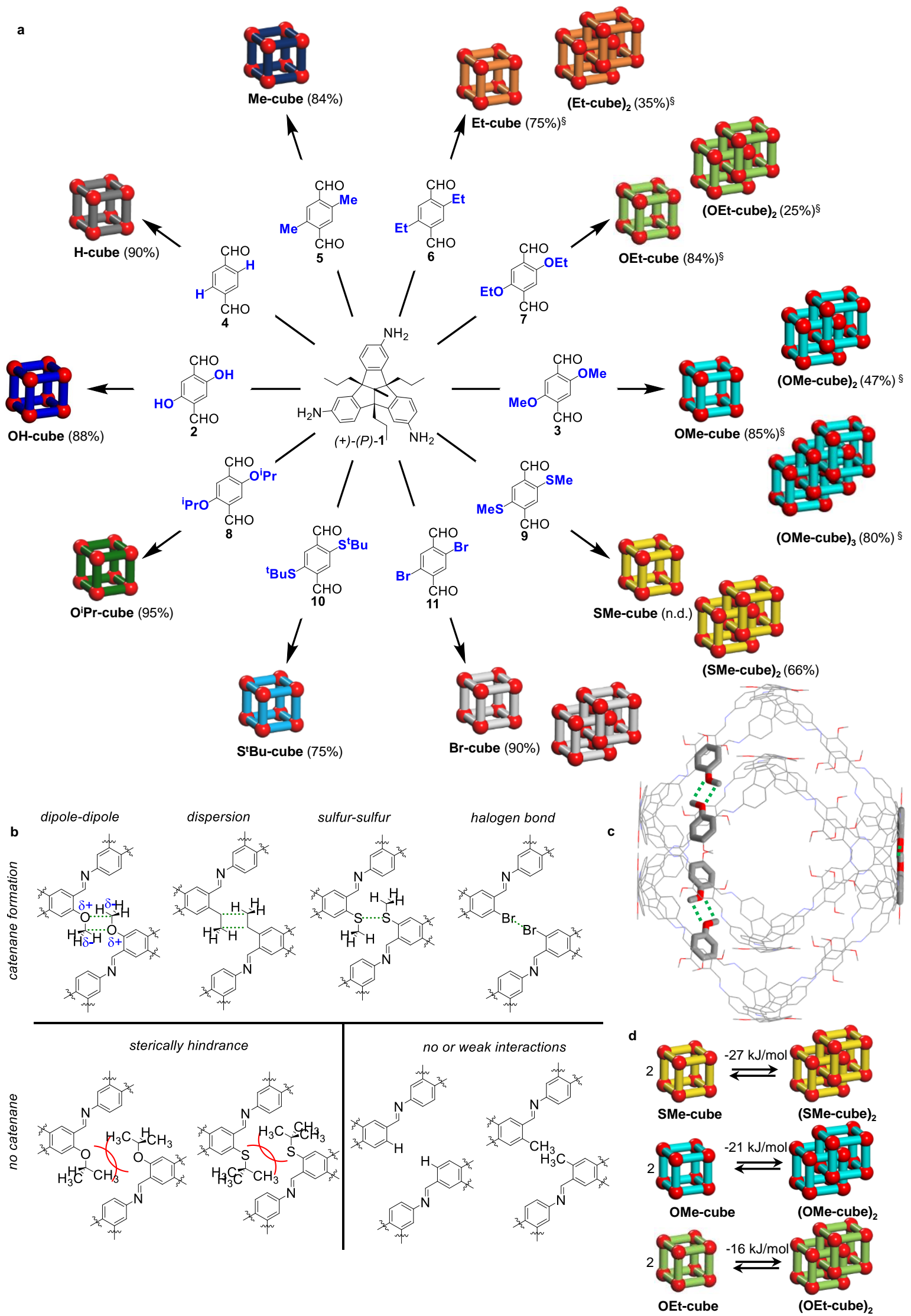

Figure 5. Cages and Catenanes. a Reactions of various dialdehydes with TBTQ triamine 1, giving cages (left side) or catenated cages (right side). b Summary of interactions resulting in catenane formation or their exclusion. c Possible conformational arrangement of the two interlocked cages with spatial arrangement of methoxy groups interacting via weak dipole-dipole forces (green dotted lines). d Gibb's energy for catenation events determined by NMR spectroscopy. ${ }^{\S}$ yields are given for optimized reactions each. 


\section{Conclusions}

An unprecedented dimeric and trimeric cage catenane formation based on week (and a priori non-directing) local dipole-dipole-interactions (so called Keesom interactions) of methoxysubstituents has been observed. By varying the substituents of the used 1,4-benzene dialdehydes electronically as well as by steric demand, the hypothesis was strengthened, because as soon as different alkoxy-substituents with similar Hammett parameters but of various bulkiness were present, those dialdehydes with bulky substituents ( whereas those with methoxy- and ethoxy-substituents did. Changing the methoxy groups to less polar ethyl groups decreased catenane formation significantly, because now the dispersion interaction is decreased. In case there is only a methyl- or no substituent at the dialdehyde the intermolecular forces are too week to foster catenane formation. Finally, we concluded that dialdehydes with substituents that can undergo other (stronger) interactions such as chalcogenchalcogen or halogen-halogen bond formations, should be beneficial to catenane formation and indeed with thiomethyl substituents a clear reaction to (SMe-cube) 2 was observed, having a 6 $\mathrm{kJ} / \mathrm{mol}$ higher Gibb's enthalphy for catenane formation than the (OMe-cube)2.

This motif of week dispersion interactions as driving force for catenation of shape-persistent organic cages allow to further study the influence of subtle structural changes to understand events of dynamic covalent chemistry of larger and more complex structures as well as to construct e.g. poly[n]catenated cages with $n>3$.

\section{Methods}

Synthesis of (OMe-cube)2 To a solution of TBTQ 1 (20 mg, $0.0429 \mathrm{mmol}, 1$ equiv) and 2,5dimethoxy-terephthaldehyde 3 (12.6 mg, $0.0644 \mathrm{mmol}, 1.5$ equiv) in chloroform (deuterated, 4 $\mathrm{mL})$ in a screw-capped $8 \mathrm{~mL}$ glass vial, a catalytic amount of TFA $(0.4 \mu \mathrm{L}, 0.0052 \mathrm{mmol}, 0.01$ equiv, $12 \mathrm{~mol} \%$ ) was added and the reaction mixture was stirred at RT for 3 days. Afterwards, the crude reaction mixture was washed with aq. $\mathrm{K}_{2} \mathrm{CO}_{3}$ solution $(0.25 \mathrm{M}, 3 \times 2 \mathrm{~mL})$, dried over 
$\mathrm{Na}_{2} \mathrm{SO}_{4}$ and concentrated under reduced pressure. The resulting red colored solid was immediately dissolved in dichloromethane and purified by recycling gel permeation chromatography (rGPC) (DCM, $\left.35^{\circ} \mathrm{C}, 5 \mathrm{~mL} / \mathrm{min}\right)$ to give $14 \mathrm{mg}(47 \%)$ of (OMe-cube) 2 as a yellow solid. Mp: $315^{\circ} \mathrm{C}$ (decomposed); ${ }^{1} \mathrm{H}$ NMR $\left(600 \mathrm{MHz}, \mathrm{CD}_{2} \mathrm{Cl}_{2}\right): \delta=8.90(\mathrm{~s}, 6 \mathrm{H}, H \mathrm{C}=\mathrm{N})$, $8.87(\mathrm{~s}, 6 \mathrm{H}, H \mathrm{C}=\mathrm{N}), 8.85(\mathrm{~s}, 12 \mathrm{H}, H \mathrm{C}=\mathrm{N}), 8.82(\mathrm{~s}, 6 \mathrm{H}, H \mathrm{C}=\mathrm{N}), 8.78(\mathrm{~s}, 6 \mathrm{H}, H \mathrm{C}=\mathrm{N}), 8.65(\mathrm{~s}$, $6 \mathrm{H}, H \mathrm{C}=\mathrm{N}), 8.38(\mathrm{~s}, 6 \mathrm{H}, H \mathrm{C}=\mathrm{N}), 8.03(\mathrm{~s}, 6 \mathrm{H}, \mathrm{Ar}-H), 7.88(\mathrm{~s}, 6 \mathrm{H}, \mathrm{Ar}-H), 7.79(\mathrm{~s}, 6 \mathrm{H}, \mathrm{Ar}-H)$, $7.71(\mathrm{~s}, 6 \mathrm{H}, \operatorname{Ar}-H), 7.69(12 \mathrm{H}, \operatorname{Ar}-H), 7.53\left(\mathrm{~d},{ }^{3} J=8.4 \mathrm{~Hz}, 6 \mathrm{H}\right.$, TBTQ Ar- $\left.H\right), 7.41$ (d, ${ }^{3} J=8.4$ Hz, 6H, TBTQ Ar- $H$ ), 7.38 (d, ${ }^{3} J=8.4$ Hz, 6H, TBTQ Ar- $H$ ), 7.36-7.32 (m, 6H, TBTQ-Ar- $H$ \& Ar- $H$ ), 7.27 (s, 6H, TBTQ-Ar-H), 7.24 (s, 12H, Ar- H, TBTQ-Ar-H), 7.21 (s, 6H, TBTQ-Ar$H$ ), 7.19 (s, 6H, TBTQ Ar-H), 7.17-7.14 (m, 6H, TBTQ-Ar- $H$ ), 7.08 (d, ${ }^{3} J=8.4$ Hz, 6H, TBTQAr-H), 7.03-6.97 (m, 18H, TBTQ-Ar- $H$ ), 6.89 (s, 6H, TBTQ-Ar- $H$ ), 6.83 (d, ${ }^{3} J=8.4$ Hz, 6H, TBTQ-Ar-H), 6.78 (d, ${ }^{3} J=8.4 \mathrm{~Hz}, 6 \mathrm{H}$, TBTQ-Ar- $H$ ), 6.77 (d, ${ }^{3} J=8.4 \mathrm{~Hz}, 6 \mathrm{H}$, TBTQ-Ar- $H$ ), $6.72(\mathrm{~s}, 6 \mathrm{H}, \mathrm{TBTQ}-\mathrm{Ar}-H), 6.59\left(\mathrm{~d},{ }^{3} J=8.4 \mathrm{~Hz}, 12 \mathrm{H}\right.$, TBTQ-Ar- $\left.H\right), 6.26\left(\mathrm{~d},{ }^{3} J=7.8 \mathrm{~Hz}, 6 \mathrm{H}\right.$, TBTQ-Ar-H), 4.04 (s, 18H, OCH $H_{3}, 3.94$ (s, 18H, OCH $H_{3}, 3.90\left(\mathrm{~s}, 18 \mathrm{H}, \mathrm{OCH}_{3}\right), 3.86(\mathrm{~s}, 18 \mathrm{H}$, $\left.\mathrm{OCH}_{3}\right), 3.82\left(\mathrm{~s}, 18 \mathrm{H}, \mathrm{OCH}_{3}\right), 3.67\left(\mathrm{~s}, 18 \mathrm{H}, \mathrm{OCH}_{3}\right), 3.11\left(\mathrm{~s}, 18 \mathrm{H}, \mathrm{OCH}_{3}\right), 2.85\left(\mathrm{~s}, 18 \mathrm{H}, \mathrm{OCH}_{3}\right)$, 2.30-1.74 (m, 96H, $\left.-\mathrm{CH}_{2} \mathrm{CH}_{2} \mathrm{CH}_{3}\right) 1.71(\mathrm{~s}, 30 \mathrm{H}), 1.64(\mathrm{~s}, 18 \mathrm{H}), 1.35-1.09(\mathrm{~m}, 84 \mathrm{H}$, $\mathrm{CH}_{2} \mathrm{CH}_{2} \mathrm{CH}_{3}$ ), 1.0-0.90 (m, $\left.126 \mathrm{H},-\mathrm{CH}_{2} \mathrm{CH}_{2} \mathrm{CH}_{3}\right), 0.77-0.72\left(\mathrm{~m}, 12 \mathrm{H},-\mathrm{CH}_{2} \mathrm{CH}_{2} \mathrm{CH}_{3}\right), 0.48$ (t, $\left.{ }^{3} J=7.2 \mathrm{~Hz}, 18 \mathrm{H},-\mathrm{CH}_{2} \mathrm{CH}_{2} \mathrm{CH}_{3}\right) ;{ }^{13} \mathbf{C}$ NMR $\left(151 \mathrm{MHz}, \mathrm{CD}_{2} \mathrm{Cl}_{2}\right): \delta=156.5,155.7,155.3,155.2$, 155.0, 154.6, 154.31, 154.26, 154.2, 153.9, 153.8, 153.1, 152.7, 152.5, 152.6, 152.3, 152.2, $150.1,149.8,149.64,149.6,149.5,149.4,149.3,149.1,146.7,146.6,146.4,146.1,146.0$, 145.5, 145.4, 129.0, 128.9, 128.6, 128.55, 128.49, 127.8, 125.0, 124.6, 124.42, 124.36, 124.2, 124.0, 119.8, 119.7, 119.4, 119.04, 118.96, 118.8, 118.5, 118.4, 118.1, 117.5, 117.3, 116.1, 116.0, 111.2, 110.2, 109.83, 109.77, 109.63, 109.58, 73.5, 73.2, 73.0, 67.39, 67.35, 67.33, 67.23, 67.18, 66.9, 56.71, 56.68, 56.65, 56.61, 56.6, 56.4, 56.1, 55.4, 41.8, 41.2, 41.1, 41.0, 21.3, 21.1, 21.0, 20.9, 20.8, 20.3, 15.5, 15.4, 15.32, 15.29, 15.0, 14.9; FT-IR (neat, ATR): $\tilde{v}$ $\left(\mathrm{cm}^{-1}\right)=2999(\mathrm{w}), 2957(\mathrm{~m}), 2925(\mathrm{~m}), 2870(\mathrm{~m}), 2853(\mathrm{~m}), 1734(\mathrm{w}), 1616(\mathrm{~m}), 1593(\mathrm{~m})$, 1492 (s), 1482 (s), 1465 (s), 1410 (s), 1373 (m), 1211 (s), 1140 (m), 1043 (s), 974 (w), 882 (m), $821(\mathrm{~m}), 701(\mathrm{w})$; UV/Vis $\left(\mathrm{CH}_{2} \mathrm{Cl}_{2}\right): \lambda_{\max }(\mathrm{nm})=296,406$; MALDI-TOF (DCTB): $\mathrm{m} / z[\mathrm{M}]^{+}$ calcd. for $\mathrm{C}_{752} \mathrm{H}_{768} \mathrm{~N}_{48} \mathrm{O}_{48}$ : 11245.94, found 11245.57. Elemental analysis calcd. for $\mathrm{C}_{752} \mathrm{H}_{768} \mathrm{~N}_{48} \mathrm{O}_{48} \cdot 33 \mathrm{CH}_{2} \mathrm{Cl}_{2}$ : C 67.11, H 5.98, N 4.79, found C 66.94, H 5.91, N 4.86.

\section{Data availability}

All data supporting the findings of this study are available within the paper and its Supporting Information. 


\section{References}

1 Wasserman, E. THE PREPARATION OF INTERLOCKING RINGS: A CATENANE1. $J$. Am. Chem. Soc. 82, 4433-4434, doi:10.1021/ja01501a082 (1960).

2 Forgan, R. S., Sauvage, J.-P. \& Stoddart, J. F. Chemical Topology: Complex Molecular Knots, Links, and Entanglements. Chem. Rev. 111, 5434-5464, doi:10.1021/cr200034u (2011).

3 Gil-Ramírez, G., Leigh, D. A. \& Stephens, A. J. Catenanes: Fifty Years of Molecular Links. Angew. Chem. Int. Ed. 54, 6110-6150, doi:https://doi.org/10.1002/anie.201411619 (2015).

4 Erbas-Cakmak, S., Leigh, D. A., McTernan, C. T. \& Nussbaumer, A. L. Artificial Molecular Machines. Chem. Rev. 115, 10081-10206, doi:10.1021/acs.chemrev.5b00146 (2015).

$5 \quad$ Kay, E. R., Leigh, D. A. \& Zerbetto, F. Synthetic Molecular Motors and Mechanical Machines. Angew. Chem. Int. Ed. 46, 72-191, doi:https://doi.org/10.1002/anie.200504313 (2007).

6 Dattler, D. et al. Design of Collective Motions from Synthetic Molecular Switches, Rotors, and Motors. Chem. Rev. 120, 310-433, doi:10.1021/acs.chemrev.9b00288 (2020).

7 Schill, G. \& Lüttringhaus, A. The Preparation of Catena Compounds by Directed Synthesis. Angew. Chem. Int. Ed. 3, 546-547, doi:https://doi.org/10.1002/anie.196405461 (1964).

8 Dietrich-Buchecker, C. O., Sauvage, J. P. \& Kintzinger, J. P. Une nouvelle famille de molecules : les metallo-catenanes. Tetrahedron Lett. 24, 5095-5098, doi:https://doi.org/10.1016/S0040-4039(00)94050-4 (1983).

9 Dietrich-Buchecker, C. O., Sauvage, J. P. \& Kern, J. M. Templated synthesis of interlocked macrocyclic ligands: the catenands. J. Am. Chem. Soc. 106, 3043-3045, doi:10.1021/ja00322a055 (1984).

10 Chichak, K. S. et al. Molecular Borromean Rings. Science 304, 1308-1312, doi:10.1126/science.1096914 (2004).

11 Ayme, J.-F. et al. A synthetic molecular pentafoil knot. Nat. Chem. 4, 15-20, doi:10.1038/nchem.1193 (2012).

12 Zhang, L. et al. Stereoselective synthesis of a composite knot with nine crossings. Nat. Chem. 10, 1083-1088, doi:10.1038/s41557-018-0124-6 (2018).

13 Leigh, D. A. et al. Tying different knots in a molecular strand. Nature 584, 562-568, doi:10.1038/s41586-020-2614-0 (2020).

14 Leigh, D. A. et al. A molecular endless (74) knot. Nat. Chem. 13, 117-122, doi:10.1038/s41557-020-00594-x (2021).

15 Leigh, D. A., Pritchard, R. G. \& Stephens, A. J. A Star of David catenane. Nat. Chem. 6, 978982, doi:10.1038/nchem.2056 (2014).

16 Wu, Q. et al. Poly[n]catenanes: Synthesis of molecular interlocked chains. Science 358, 14341439, doi:10.1126/science.aap7675 (2017).

17 Fujita, M., Fujita, N., Ogura, K. \& Yamaguchi, K. Spontaneous assembly of ten components into two interlocked, identical coordination cages. Nature 400, 52-55, doi:10.1038/21861 (1999).

18 Frank, M., Johnstone, M. D. \& Clever, G. H. Interpenetrated Cage Structures. Chem. Eur. J. 22, 14104-14125, doi:https://doi.org/10.1002/chem.201601752 (2016).

19 Zhu, R. et al. Catenation and Aggregation of Multi-Cavity Coordination Cages. Angew. Chem. Int. Ed. 57, 13652-13656, doi:https://doi.org/10.1002/anie.201806047 (2018).

20 Bloch, W. M., Holstein, J. J., Dittrich, B., Hiller, W. \& Clever, G. H. Hierarchical Assembly of an Interlocked M8L16 Container. Angew. Chem. Int. Ed. 57, 5534-5538, doi:https://doi.org/10.1002/anie.201800490 (2018).

21 Ronson, T. K., Wang, Y., Baldridge, K., Siegel, J. S. \& Nitschke, J. R. An S10-Symmetric 5Fold Interlocked [2]Catenane. J. Am. Chem. Soc. 142, 10267-10272, doi:10.1021/jacs.0c03349 (2020).

22 Wang, L., Vysotsky, M. O., Bogdan, A., Bolte, M. \& Böhmer, V. Multiple Catenanes Derived from Calix[4]arenes. Science 304, 1312-1314, doi:10.1126/science.1096688 (2004). 
23 Li, Y. et al. Sulfate anion templated synthesis of a triply interlocked capsule. Chem. Commun., 7134-7136, doi:10.1039/B915548A (2009).

24 Hasell, T. et al. Triply interlocked covalent organic cages. Nat. Chem. 2, 750, doi:10.1038/nchem.739

https://www.nature.com/articles/nchem.739\#supplementary-information (2010).

25 Zhang, G., Presly, O., White, F., Oppel, I. M. \& Mastalerz, M. A Shape-Persistent Quadruply Interlocked Giant Cage Catenane with Two Distinct Pores in the Solid State. Angew. Chem. Int. Ed. 53, 5126-5130, doi:10.1002/anie.201400285 (2014).

26 Zhang, G., Presly, O., White, F., Oppel, I. M. \& Mastalerz, M. A Permanent Mesoporous Organic Cage with an Exceptionally High Surface Area. Angew. Chem. Int. Ed. 53, 15161520, doi:10.1002/anie.201308924 (2014).

27 Wang, Q. et al. Solution-Phase Dynamic Assembly of Permanently Interlocked Aryleneethynylene Cages through Alkyne Metathesis. Angew. Chem. Int. Ed. 54, 7550-7554, doi:10.1002/anie.201501679 (2015).

$28 \mathrm{Li}$, H. et al. Quantitative self-assembly of a purely organic three-dimensional catenane in water. Nat. Chem. 7, 1003-1008, doi:10.1038/nchem.2392 (2015).

29 Li, P. et al. De Novo Construction of Catenanes with Dissymmetric Cages by SpaceDiscriminative Post-Assembly Modification. Angew. Chem. Int. Ed. 59, 7113-7121, doi:10.1002/anie.202000442 (2020).

$30 \mathrm{Xu}$, S. et al. Catenated Cages Mediated by Enthalpic Reaction Intermediates. CCS Chemistry 0, doi:doi:10.31635/ccschem.020.202000360.

31 Beaudoin, D., Rominger, F. \& Mastalerz, M. Chiral Self-Sorting of [2+3] Salicylimine Cage Compounds. Angew. Chem. Int. Ed. 56, 1244-1248, doi:https://doi.org/10.1002/anie.201610782 (2017).

32 Wagner, P. et al. Chiral Self-sorting of Giant Cubic [8+12] Salicylimine Cage Compounds. Angew. Chem. Int. Ed. 60, 8896-8904, doi:https://doi.org/10.1002/anie.202016592 (2021).

$33 \mathrm{Xu}, \mathrm{D} . \&$ Warmuth, R. Edge-Directed Dynamic Covalent Synthesis of a Chiral Nanocube. J. Am. Chem. Soc. 130, 7520-7521, doi:10.1021/ja800803c (2008).

34 Beaudoin, D., Rominger, F. \& Mastalerz, M. Synthesis and Chiral Resolution of C3Symmetric Tribenzotriquinacenes. Eur. J. Org. Chem. 2016, 4470-4472, doi:10.1002/ejoc.201600890 (2016).

35 Beaudoin, D., Rominger, F. \& Mastalerz, M. Chiral Self-Sorting of [2+3] Salicylimine Cage Compounds. Angew. Chem. 129, 1264-1268, doi:10.1002/ange.201610782 (2017).

36 Bhat, A. S. et al. Transformation of a [4+6] Salicylbisimine Cage to Chemically Robust Amide Cages. Angew. Chem. Int. Ed. 58, 8819-8823, doi:10.1002/anie.201903631 (2019).

37 Schneider, M. W., Oppel, I. M., Griffin, A. \& Mastalerz, M. Post-Modification of the Interior of Porous Shape-Persistent Organic Cage Compounds. Angew. Chem. Int. Ed. 52, 3611-3615, doi:10.1002/anie.201208156 (2013).

38 Schick, T. H. G., Rominger, F. \& Mastalerz, M. Examination of the Dynamic Covalent Chemistry of [2+3]-Imine Cages. J. Org. Chem. 85, 13757-13771, doi:10.1021/acs.joc.0c01887 (2020).

39 Gilli, G., Bellucci, F., Ferretti, V. \& Bertolasi, V. Evidence for resonance-assisted hydrogen bonding from crystal-structure correlations on the enol form of the .beta.-diketone fragment. $J$. Am. Chem. Soc. 111, 1023-1028, doi:10.1021/ja00185a035 (1989).

40 Keesom, W.H., The second viral coefficient for rigid spherical molecules, whose mutual attraction is equivalent to that of a quadruplet placed at centre. KNAW, Proceedings 18 I, 636646, (1915) Amsterdam.

41 Ueberricke, L. et al. Triptycene End-Capped Quinoxalinophenanthrophenazines (QPPs): Influence of Substituents and Conditions on Aggregation in the Solid State. Chem. Eur. J. 25, 11121-11134, doi:10.1002/chem.201902002 (2019).

42 Greenaway, R. L. et al. High-throughput discovery of organic cages and catenanes using computational screening fused with robotic synthesis. Nat. Commun. 9, 2849, doi:10.1038/s41467-018-05271-9 (2018). 
43 Wagner, J. P. \& Schreiner, P. R. London Dispersion in Molecular Chemistry-Reconsidering Steric Effects. Angew. Chem. Int. Ed. 54, 12274-12296, doi:https://doi.org/10.1002/anie.201503476 (2015).

44 Hansch, C., Leo, A. \& Taft, R. W. A survey of Hammett substituent constants and resonance and field parameters. Chem. Rev. 91, 165-195, doi:10.1021/cr00002a004 (1991).

45 Charton, M. Nature of the ortho effect. II. Composition of the Taft steric parameters. J. Am. Chem. Soc. 91, 615-618, doi:10.1021/ja01031a016 (1969).

46 Gleiter, R., Haberhauer, G., Werz, D. B., Rominger, F. \& Bleiholder, C. From Noncovalent Chalcogen-Chalcogen Interactions to Supramolecular Aggregates: Experiments and Calculations. Chem. Rev. 118, 2010-2041, doi:10.1021/acs.chemrev.7b00449 (2018).

47 Cavallo, G. et al. The Halogen Bond. Chem. Rev. 116, 2478-2601, doi:10.1021/acs.chemrev.5b00484 (2016).

\section{Acknowledgements}

The authors like to thank the European Research Council ERC in the frame of the consolidators grant CaTs n DOCs (grant no. 725765). We further would like to thank Dr. Julian Holsten (Universität Dortmund, Germany), Dr. Sven M. Elbert, Margit Brückner and Dr. Frank Rominger, (all Ruprecht-Karls-Universität Heidelberg) for their efforts in getting single-crystal X-ray structures of the here described cages and catenanes. Support by the state of BadenWürttemberg through bwHPC and the German Research Foundation (DFG) through grant no INST 40/5751 FUGG (JUSTUS 2 cluster) is acknowledged.

\section{Author information}

\section{Affiliations}

Dr. Bahiru P. Benke, M.Sc. Tobias Kirschbaum, Dr. Jürgen Graf, Prof. Dr. Michael Mastalerz, Organisch-Chemisches Institut, Ruprecht-Karls-Universität Heidelberg, Im Neuenheimer Feld 270, 69120 Heidelberg, Germany

\section{Contributions}

B.P.B. found the catenation reaction. M.M. and B.P.B conceived and planned the project. B.P.B. did all the experimental work. M.M. and B.P.B. analysed and interpreted the results. T.K. performed DFT calculations. J.G. was responsible for the NMR experiments, especially in helping elucidating the structure of catenanes. M.M. and B.P.B prepared the manuscript, which was edited by all authors.

\section{Corresponding author}

Correspondence to michael.mastalerz@oci.uni-heidelberg.de

\section{Ethic Declarations}

\section{Competing interests}

The authors declare no competing interests. 